\title{
Information Sharing Behaviour of Complex and Extended Organisations
}

\author{
Bata, P. P. ${ }^{1}$, Norman, A. ${ }^{1}$, \& Allen, D. ${ }^{1}$ \\ ${ }^{1}$ Division of Management, Leeds University Business School, University of Leeds, United Kingdom \\ Correspondence: Bata, P. P., Division of Management, Leeds University Business School, University of Leeds, \\ United Kingdom. E-mail: polpitabata07@yahoo.com
}

Received: June 28, 2020

Accepted: August 16, 2020

Online Published: October 20, 2020

doi:10.5539/ijbm.v15n11p41

URL: https://doi.org/10.5539/ijbm.v15n11p41

\begin{abstract}
The information sharing behaviours observed in extended organisations involve the use of dedicated specialised teams and groups. This study presents theoretical evidence, drawing on Activity Theory as an analytical lens, linking specialised teams in such complex and extended organisations to conditions which may lead to information sharing failures. These failures are apparent through tensions and contradictions examined in the activity system which helped in identifying failures in the formal systems and emergent behaviours to (or "intending to") resolve them. Results from this study show that information sharing behaviours in an extended organisation are driven in part at least by the team's need and ability to share information with members of the team (formed to) dealing with an information sharing failure resulting in an organisational problem and aimed at achieving a common shared goal in the relationship. There is an established link showing that information sharing in the setting supports and enhances the exchange of ideas and information between partners due to the complementing needs of services thus helping in reducing extension problems and, thereby, providing a coping strategy for the central organisation. Amongst the importance of information sharing in the setting is the ability to forecast uncertainties as a result of better understanding of each partner's capabilities and strength. Complexity was observed to be a factor that triggers information sharing failure in extended relationships and dependencies. This occurs when there is no congruence between information deliveries amongst all the collaborating partners.
\end{abstract}

Keywords: activity theory, complex and extended organisations, complexity, extension, information sharing and information behaviour

\section{Introduction}

The global nature of the modern business in today work environment is complex. This complexity is as a result of necessity and a means of reacting to the way the world works which has forced many institutions to rethink the opportunities available to them by way of extending beyond their boundaries and embracing the opportunities available to them. Such necessity will drive extension and with extension comes the possibility of complexity. Many of these types of extension are in the form of partnering and collaboration which is complex and involves external entities (Lawson et al., 2009). which provide specialisation and temporary services which the central organisation cannot otherwise provide.

Some of the relationships in the collaboration may be based on, and governed by, well-articulated and formal contractual arrangements while others may be based on evolved and informal arrangements which, while accepted and accommodated, are subject to far lower levels of formality and governance facilitating flexible working as explained by new work settings (Holman et al., 2003)

The situation is challenging and requires an understanding between all partners involved. It is also one with high possibility of information sharing failures due to the complexity involved and the lack of understanding of the nature and types of these extended relationships referred to as complex (IRM, 2014).

This kind of relationship is increasingly becoming common, and its complexities and challenges remain understudied in work related information science area (Provan and Lemaire, 2012). The underlying assumption here is that it is more likely that information will tend not to be shared appropriately in organisations that are extended and complex. This is because, as complexity and extension increases there are also more potentials for failures. These potential failure points can, if realised, reduce such organisations' effectiveness, leading to lost 
productivity and efficiency, as stated by Proven and Lemaire (2012).

Information sharing has been identified as the link through which extended organisation manage to keep in touch with collaborating partners and become productive and efficient in achieving the organisational objectives by way of effective communication (Provan \& Lemaire, 2012).

In understand these extension-based complexities, we found Activity Theory (AT) was a powerful tool for understanding the stakeholders involved in different activity systems, different tools they engage with, the community as a whole and the effect of rules on the relationship. The phenomena observed are explored and analysed.

The paper has as its objective exploring collaborative information sharing in complex and extended organisations. Its aim is to explore emerging practice in the setting which is complex and extended and address the question of how complexity and extension influences collaborative information sharing. The paper is aimed at contributing to knowledge through empirical evidence by exposing the information sharing behaviours of extended organisations and illuminating practice in such settings. The paper also presents theoretical evidence that links extended groups with complexities and more possibilities of information sharing failures.

The paper is structured as follows. Section 2 is a brief summary of the literature development and understanding of the setting. Section 3 presents the methodology employed in the study and Section 4 provides the empirical evidence that supports the findings of the paper. Finally, section 5 gives the implications, and discussion of the findings.

\section{Materials Information Sharing Behaviours and Drivers in Complex and Extended Organisations}

Information has been described as an ingredient of growth and a form of knowledge (Hilbert, 2016), the amount of information one acquires having a direct effect on the environmental pattern, and the two (information and the amount received) are linked to growth. Information sharing, therefore, is considered essential for inter and intraorganisational communication as the process provides a platform for the exchange of ideas between partners (Huo et al., 2013). Evidence exists to show the relationships between information sharing and a better understanding of partner's capabilities (Liu et al., 2015). Additionally information sharing helps in coping with environmental uncertainties of partners as information about their operation and the external environment is made available to the collaborating partners (Wong et al., 2015)

The importance of information and its ability to be shared can, therefore, not be ignored in general (Pilerot, 2014) and especially in extended organisations. Among the uses of information are; understanding of partner's capabilities (Liu et al., 2015); coping with environmental uncertainties (Wong et al., 2015); exchange of information and ideas between partners (Huo et al., 2013). Other uses are for decision making, planning, knowledge acquisition; understanding other stakeholder's perspectives, and as a means of achieving mutual benefit (Mishra, 2012).

Information sharing behaviours as argued by Robson and Robinson (2013) combine the information seeking aspect with communication and also incorporate factors like work role, task, information needs, demographic and environmental constraints to understand reasons for sharing. The positive use of information sharing according to Lee et al. (2000) is a primary strategy in the achievement of organisational success. Yang and Maxwell (2011) described information sharing as a process that increases both efficiencies and performance. Similarly, ChengalurSmith et al. (2012) state that the act of sharing information is nowadays easier due to technological advancement, however, it can still be a complicated task. More so, information sharing according to Mishra et al. (2011) is affected by needs, social dimension, technology and time factors, as these factors can affect the abilities and needs of an organisation to share information. However, Yang and Maxwell (2011) describe the technological perspective, the organisational viewpoint, (internal) politics and policies as factors that can have an adverse effect on the ability to share effectively.

The importance as stated above can be linked to the reasons why most studies undertaken in the area of information sharing pay attention to different work contexts. The work settings studied include the task (Allen et al., 2014; Allen and Wilson, 2005); disciplines (Pilerot, 2014); supply chain (Chengalur-Smith 2012) and the Public sector (Yang and Maxwell, 2011). However, there is a limited amount of work which has examined the information sharing behaviours of teams in complex and extended organisations, as in this paper.

Many organisations today are involved in inter and intra-organisational networks with a consequent shift towards a business environment that is complex both regarding its operation and relationship. The relationships existing between different arms of the organisations, different structures or different patterns need to be coordinated and regulated to (or "intending to") understand organisational links. A study by the Institute of Risk Management (IRM, 
2014) looked at extended enterprises as a complex network of relationships that support both the public and private sectors in modern economies.

Rouse (2012) defines extended enterprises as organisations whose success depends on networks of relationships, meaning that they cannot function in isolation. Similarly, Farrel (2008) sees extension as a representation of relationships that cut across entities having direct or indirect things in common and whose relations affect each other. This type of organisation operates independently but has a shared object (relationship) as a result of market, contracts or agreements.

This paper sees extension as the extent to which an organisation has to collaborate across a set of other groups to meet the aims it has to achieve. Complexity is bound up with extension in many cases in the sense that expansion will tend to bring complexity with it as the organisation has to accommodate a range of diverse stakeholders and ways of working, though complexity may also arise without significant extension or independent of it. The paper concentrates on extension related complexities within and across organisations with the associated potentials for information sharing failures caused as a result of these extensions.

The attributes of complex organisations shown in the IRM (2014) study reveal that they are difficult to control because they are unpredictable, but that they are also adaptive due to unexpected issues which are likely to arise in the event of trying to solve particular problems. Such relationships may necessitate many disciplines working together in a new way and managing such interactions by way of innovations through the correct principles, shared ethics, shared values and acceptable behaviours. Though extended and complex organisations according to IRM (2014) are increasingly becoming common in today's working environment, their complexities and challenges remain an understudied area (Provan \& Lemaire 2012).

A key driver for this paper is that, while extended and complex organisations will have areas where information is shared effectively, there are also areas and instances of failure associated with the lack of information sharing (Mihm et al. 2010). Such failures in information sharing will have their roots in many causes, and the elimination of all such failures is an ideal state that is unlikely to be achieved. Where such failures occur the impacts of them may be relatively minor or may have significant implications, and this may reduce such organisations' effectiveness, leading to lost productivity and efficiency (Provan and Lemaire (2012). According to Jagdey and Browne (1998 p. 218) among the reasons for the creation of extended relationships which often engender complexity are; a measure to reduce the development process involving materials; acts as a way to increase information sharing; for product and infrastructure development; to increase speed of required products to reach market and as a means for improved delivery time. Others includes; a way of acceptance of an expansive life cycle orientation and provision of dynamic organisations and expansion of organisational vision

An example of the importance of information in the case study organisation is seen in the greater need to relate by way of sharing information with different organisations through teams as a way of achieving success and gaining mutual benefit based on a shared object which is the concept of the 'credible certificate'. However, there is reduced control over the entirety of the process due to the complexity attached to such extension, or the relationships involving the use of different technology, operational proceedings and interpretations of law as it affects the teams.

Landy and Conte (2016) argued for the use of groups to address productivity problems and to increase the quality and quantity of product. Literature on teams that highlights and discusses their different aspects e.g. CamarinhaMatos (2004) identify and characterise collaborative organisations; Belbin (2012a) looked at management of teams, Belbin (2012b) looked at team's role at work and Belbin (2012c) studied how people and jobs can be connected beyond the team. Definitions of 'team' are manifold but have commonalities; Katzenbach \& Smith (1993) define a team as a small number of people with complementary skills who are committed to a common purpose, performance goals, and an approach for which they hold themselves mutually accountable. Engestrom (2008) similarly, describes teams as people with complementary skills committed to an ideology to achieve a goal. Richards et al. (2012) describe teams as those responsible for producing an output or that share a common goal. According to them, characteristics of a team include; creating a positive atmosphere which allows work to take place; provision of sound communication with all members, having shared goals and constructive conflict to build each other and find the best way to achieve the target of the team. Though teams are sometimes referred to as groups, they are definitionally different. Groups are between three and nine with a common purpose meeting and communicating through a medium to aid the achievement of their goals (Tuckman \& Jensen, 1977), but they do not necessarily have the complementary skills teams (Egolf \& Chester, 2013) are suggested to have. Similarly, Landy \& Conte (2016) differentiate the two as by defining 'group' as individuals working together, or sharing resources while teams are individuals whose task are interdependent.

Teams are also given different names for different reasons and according to different industries. Some of which 
are; Task Force (Force, 2008); Committees (Lund, 2015); Self-managed teams (Aznar et al., 2012). Others are Cross-functional teams (Aime et al., 2014); Virtual teams (Hoch and Kozlowski, 2014); high-performance teams (Richards et al., 2012).

Most of these are a form of temporary group formed for a short duration to achieve a stated goal (Tannenbaum et al., 2012). However, there are some of the temporary teams used for longer periods, such as administrative teams in an organisation.

Two types of temporary teams are familiar, the formal and informal temporary teams. Formal teams could be deliberate teams created to carry out a specific task, for example, command teams. Informal teams, on the other hand, include teams that may emerge as a result of emergencies or uncertain conditions which require immediate action.

Temporary teams as in the case of complex and extended organisations are formed for a short duration to achieve a stated goal (Tannenbaum et al., 2012) by way of problem-solving. It has been observed in the case study organisation that teams are used to achieve specific tasks to support other inputs and for information sharing. An example from the case setting is the monitoring team - a team to monitor the conduct of examinations, share information within the team of monitors and solve problems within their area of jurisdiction. However, some of the problems which are complex, and require expertise to handle, are solved by knots that form to handle such specialised knowledge problems. Engeström et al. (1999) described this as knot-working which is when problems arise in organisation, knots form to deal with such problems based on expertise and specialised members forming the knots

Therefore, this paper reports the use of teams in complex and extended organisations as a way of problem-solving and sharing information using different innovations which aid the achievement of the goals and bridge the gap that causes failures.

\section{Methodology and Theoretical Standing}

In trying to understand how people in complex and extended settings work and construct their understanding and knowledge of their world, a social constructivist worldview was used to help answer the question of what, how and why (Schwandt, 1994). Therefore, an interpretive research paradigm was embraced which views the world as formed by individual's perception of what reality is and that such truth varies between people and is socially constructed from one person to another (Tracy, 2013). Therefore, this study is an account of the behaviours of individuals in their natural working environment.

The assumptions which underlie the researcher's approach (interpretive research), are drawn from organisational research which is concerned with giving meaning to patterns of actions which in turn result in meaning for organisations (Smircich, 1983). The reason for the choice of interpretive paradigm and social constructivist view of the world is due to the nature of the setting the researcher is looking at which is complex and extended. The research is interested in a granular analysis of the failures in information sharing within these complex and extended environments which also drives the interest in the behaviours that people use to share information is such setting with a view to address and cope such failure. A survey cannot cover these phenomena that the research is interested in by assigning yes or no answers. Rather it needs to be investigated in a more qualitative way. Therefore, a qualitative case study was granted by an examination board, and the organisation was selected because its functioning, and practice falls within the categorisation of this research (organisation with extended relationships) and can be considered as complex as it is characterised by;

1) The organisation, which is a public exams organisation enters both contractual and social types of relationship channels toward a shared object characterised as the 'credible certificate'.

2) That the organisation extends further their relationships and dependencies on getting the examination right by using different specialised teams. Examples include, team of exam monitors, team of markers, team of supervisors and many others. With these different extended teams, it becomes difficult and complex for the organisation to effectively and fully share information with all its stakeholders due to different information sharing needs and different channels needed.

Activity Theory (AT) provides the lens through which to understand and investigate the phenomena the study is interested in through semi-structured interviews, observations and document analysis. The reason for the use of activity theory in this study is that AT is seen as a method/tool that is focussed on purposeful human activity and provides a framework for investigation of information sharing which is undertaken as such a purposeful human activity. AT, therefore, is a way of looking at and trying to understand this phenomenon and particularly, its ability to handle multi-events which suit the area of the study - being complex and extended settings. The setting has a 
range of different rules and norms and diverse communities; there are various tools involved, different expectations and different motivations. All of which AT accommodates and provides an explanatory framework for understanding. Equally, AT helps in indicating where and how contradictions and tensions have led to failures in information sharing, the collapse of information sharing processes and the improvements perceived to be needed in the system, as discussed in information sharing and information behaviour literature.

For the understanding of the complexities and challenges in a complex and extended organisation as given by IRM (2014) and Mihm et al. (2010). Activity Theory was used as an overarching framework and tool for understanding the dialogue between different communities, networks of interrelated activities and division of labour (Engestrom, 1999). Activity Theory also helps in determining the best methodology as it defines the subjects, communities and types of division of labour in this paper. AT has evolved through a number of 'generations' from its original Soviet roots and third generation activity theory has significantly informed practice for this article, however, to further understand the deficiencies cause by complexities elements drawn from fourth generation AT (4GAT) may be used according to Khayyat (2016) to complement the third generation AT.

The framework was used in defining the subjects who became the sample in the investigation, designing the interview questions and understanding the tools employed by the subjects, understanding how rules applied to all the communities in the study and the understanding of the different division of labours involving the extended partners. An example of the activity system (whose outcome is the credible certificate) is outlined in figure 1.

The examination is the object that brings different organisations (schools/universities/ the examination Board, Government) working towards the product (conceptualised as the "credible certificate). This same product of an examination process serves the needs of a complex set of stakeholders, but ones who all have a common need for the examination process to be fair, effective and efficient. Therefore, such organisations which depend on the credible certificate, have different interests; some are getting student enrolment (school); admitting new students (Universities); or upgrading the skilled worker (work organisations). Consequently, different activity systems are working toward the object with a view to making the certificate a credible one that can be used by all. (Note: that the credibility of the certification is paramount and is the factor that must be protected by the shared object of exams). The object, conceptualised as a shared object, has different attributes that qualify the credibility of the certificate. For some organisations, the setting, quality assurance, and processing of an examination is what contributes to credible documents. For another body, the monitoring, recognition and acceptance of the testing and certificates lead to the credibility of the certificate, for another, an employer for example, emphasis goes onto the content, and rigour of the examination process leading to the credibility of the certificate.

The method used is a semi-structured interview and a case study approach chosen from an examination board and its stakeholders. A total sample of 46 interviewees was used for the study based on non-probability sampling (both convenience and purposive). The sample included 15 members of management that were willing to take part and 12 middle-level staff from the organisation. Others are the users of the agency's certificates, 8 in number, and 11 different stakeholders including; staff from similar agencies, staff from supervising ministry, school proprietors, and university staff.

The reason for the use of non-probability sampling is its association with qualitative research for selecting the sample population. This method allows the selection of a sample to reflect some particular group features of the population which are not statistically intended but purposive (Mason, 2002) and also represents some specific features that will allow more detailed understanding of the researcher's aim i.e. convenience due to the relative ease of access and purposive due to the need to reflect the identified groups from the use of AT.

To make sense of the qualitative data collected Nvivo was used to undertake four core processes: integrating the data; organising it; exploring as a result of querying the data and, finally, interpreting it. 85 nodes and six themes were identified among which are complex and extended, teams and knots, information sharing behaviours, information failures looking at tensions and contradictions, achieving organisational objectives and finally culture, rules and norms. 


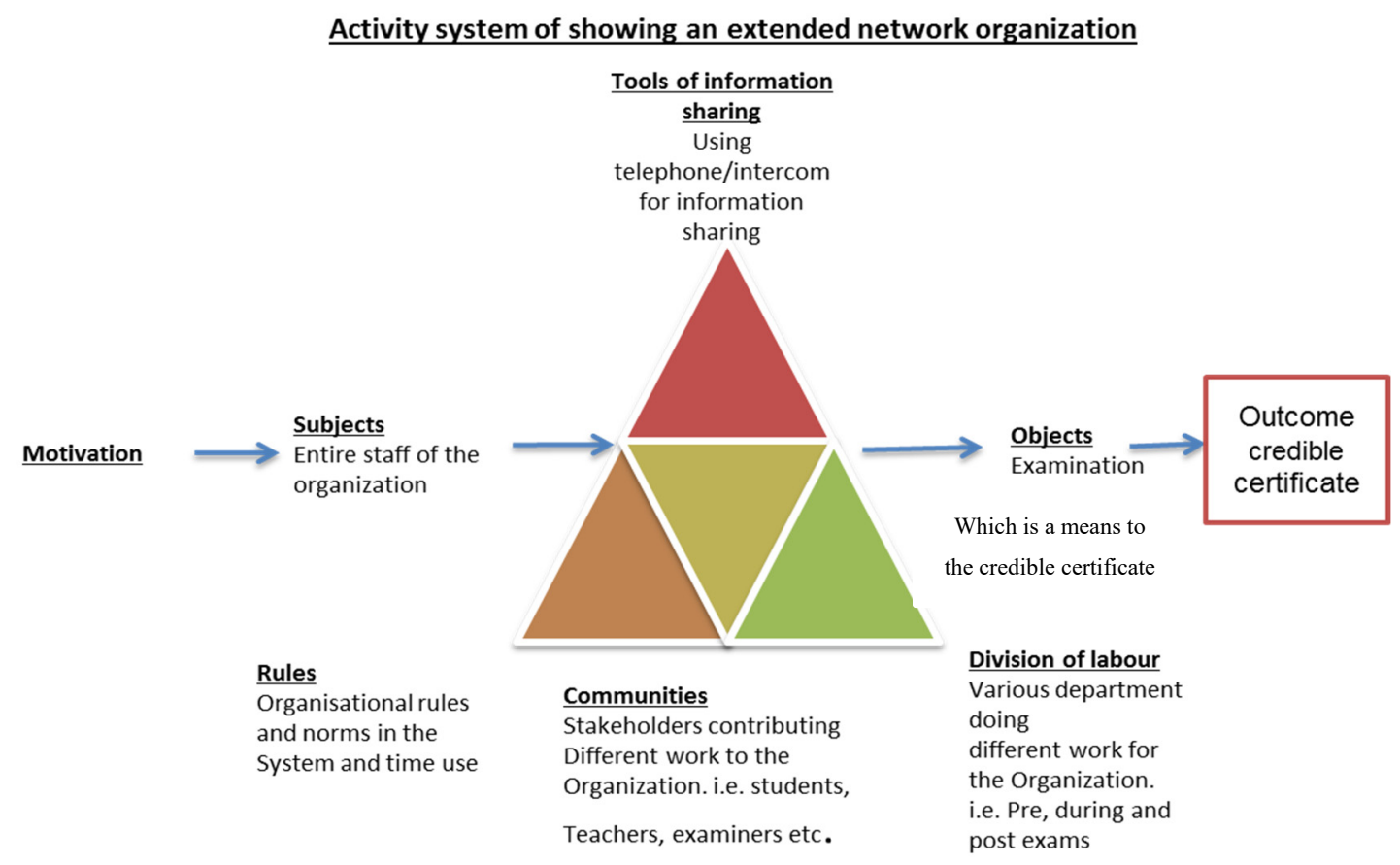

Figure 1 Activity model of examination setting showing expended relationship

Source: Authors (Bata) 2018.

\section{Findings and Analysis}

The paper found that in complex and extended organisations, there is a common shared object that influences extension through different forms of collaboration. This shared object is vital and needs efficient information sharing among all the collaborating partners. One of the stakeholders who has a long-standing relationship with the case study organisation described the relationships as complex due to;

"Different components/group brought together to achieve the same goals".

The extract above supports Farrel (2008) who sees such relationships as entities having direct or indirect common object(s) and whose relations affect each other. Exploration of the case study organisation found the credible certificate as the shared object that brings different stakeholders together in an extended relationship, e.g. school proprietors who collaborate with the examination board to produce candidates for examinations which are then used for University entry. Such Universities are also stakeholders as they take part in supervising the exams and using the certificates for their admissions processes. Other stakeholders include those facilitating the process (as opposed to the product) of the examination and these include the group of markers, item generation team and many others. All these stakeholders play a decisive role in the administration of the exams by producing some of the specialisation needed for the exams in the form of teams as a division of labour. These teams all need information to work with but have different needs and use different communication channels with various technology, however, when commonality of needs and technologies cannot be provided, it potentially affects the credibility of the certificate as the exams may be affected by some forms of compromises or failures in information sharing resulting from these differences and causing deviation from original practice.

The case study example shows the central activity system is the examination. However, three different nested events (activities) are also found within the overall activity system which are the pre-examination, the exams and post testing stages, furthermore, within each stage, there are also sub-activities. Apart from the organisation staff, most of the collaborating partners are external to the examination board, and they provide a specialised service to the board. Therefore, it is not out of place to say that the relationships in such extended collaboration are dedicated. However, such relationships can be complex which is driven by extension, and this is diagnosed by tensions and contradictions where the communication tools are not congruent (i.e. using non congruent tools of communication between collaborating partners or if there is conflict in rules/implementations and different norms and practice). On the aspect of tools, a stakeholder (a director and head of department of another examination organisation) highlights that; 
"Information comes in different forms and platforms which needs to be transcribed into certain format to make it readable for the target group"

Using Activity Theory as the framework, figure 2 highlights some areas of tension and contradiction in the activity system. To fully understand the failures and the innovations in the processes addressed it is necessary to try to identify the contradiction at all levels of the activities. These failures are manifested through deviations from the fundamental norms and practice in the system, also called disturbances, and are responsible for causing constant instability in the system (Engestrom, 2000). Tensions and contradictions are significant in this paper as they show the possible areas of breakdown in the overall activity system, or where possible tensions manifest. It is also said to be where operations are misaligned causing potential failures to the system. This misfit is between elements of an activity system or between activities. Historical information is also needed to judge some occurrences in the overall activity system to know and understand the areas of the misfit. Expensive learning becomes useful at this stage where stakeholders need to join forces and contest the extension driven complexity causing misfit in the overall activity system to (or "intending to") protecting the credibly of the certificate (Engeström, 2015).

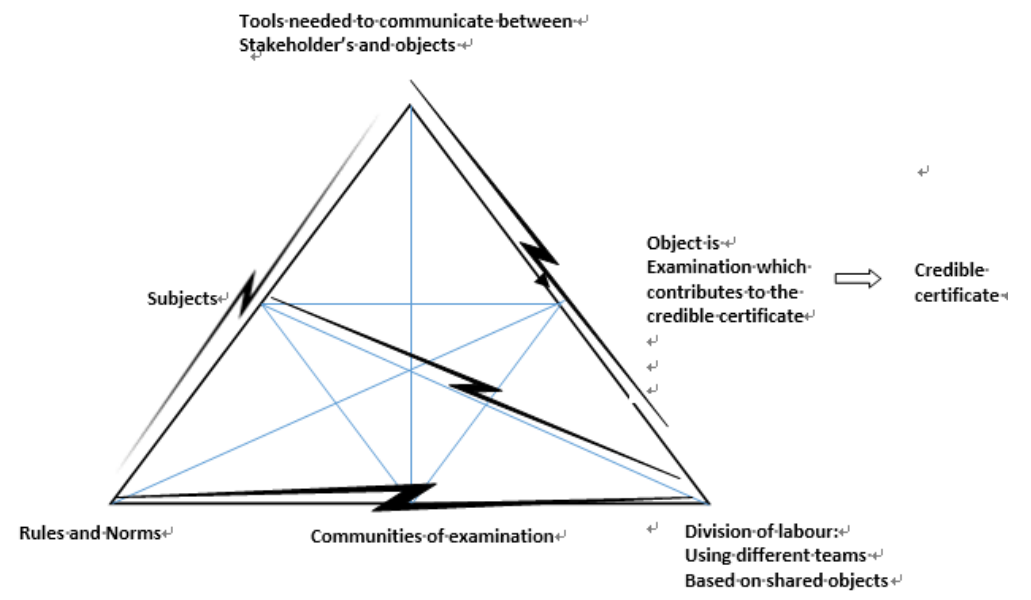

Figure 2. Areas of tensions and contradictions in the examination activity system

Source: Authors. (Bata). 2018.

The activity model in figure 2 highlights areas of contradictions with subjects, tools, rules, norms, the division of labour with the communities which affects the object and the outcome. First, the needs have been established as important to communicate with various stakeholders for the achievement of goals. However, there is a diminished (reduced) ability to achieve this need. Table 1 explains the contradictions identified in Figure 2, with some examples of how it affects extended relationships thereby causing reduced ability which in turn affects the object contributing to the credibility of the object. 
Table 1. Analysis of areas of tension and contradictions

\begin{tabular}{|c|c|c|c|}
\hline $\mathbf{S} / \mathbf{N}$ & Subjects/Tools/Objects & Needs/ Tensions and Contradictions & Ability/ Outcome \\
\hline 1 & $\begin{array}{l}\text { Organisations Staff are having to } \\
\text { use communication tools to reach } \\
\text { out to the various stakeholders on } \\
\text { the various stages involved in the } \\
\text { pre examination stage. } \\
\text { Tools, division of labour and the } \\
\text { object (examination) where the } \\
\text { lack of communication exist due to } \\
\text { the difference in tools. } \\
\text { Object } \\
\text { Coordinate the various stages of the } \\
\text { examination starting with } \\
\text { preparation of posters, media } \\
\text { adverts, flag-up sales of forms, } \\
\text { appoint supervisors, conduct } \\
\text { briefing, prepare mark and } \\
\text { attendance sheets to the post } \\
\text { examination stage. } \\
\text { Example to send out } \\
\text { Using email to to } \\
\text { information as it relates to } \\
\text { registration of examination. } \\
\text { Example } 2 \text { Inability to communicate to } \\
\text { supervisors who are meant to } \\
\text { handle the exams process. }\end{array}$ & $\begin{array}{l}\text { Tensions and Contradictions } \\
\text { We see T\&C between tools and subjects. } \\
\text { Example } 1 \\
\text { Some of the stakeholders do have the } \\
\text { computer but no internet to enhance the } \\
\text { communication ability. } \\
\text { Example } 2 \\
\text { Some use different means of communication } \\
\text { which is different from that of the } \\
\text { collaborating organisation. }\end{array}$ & $\begin{array}{l}\text { There is a reduced ability to get the right } \\
\text { information or share same due to the conflict in } \\
\text { tools of delivery. } \\
\text { Example } \\
\text { Candidates for the examination are having to be } \\
\text { left out on important information or changes to } \\
\text { examination calendar as a result of the schools } \\
\text { not having the right communication tool. } \\
\text { Outcome } \\
\text { The credibility of the certificate is threatened as } \\
\text { the shared object is affected. } \\
\text { Example } \\
\text { Registration is reduced due to inability to } \\
\text { register. } \\
\text { The conduct of the exams is threatened with } \\
\text { candidate not having the right information }\end{array}$ \\
\hline 2 & $\begin{array}{l}\text { Staff and Rules/Norms } \\
\text { Object: Using the same rule with } \\
\text { one organisation in different ways. } \\
\text { Example } \\
\text { Mr A commits and offence but } \\
\text { because he is a brother of a director } \\
\text { he was not punish. Mr B commits } \\
\text { the same office and gets } \\
\text { punishment for that. } \\
\text { Rules and communities. }\end{array}$ & $\begin{array}{l}\text { Where the other collaborating bodies have a } \\
\text { different rule guiding their conduct. } \\
\text { Example } 1 \\
\text { Senior service regulation and that of junior } \\
\text { staff guides the case study organisation. } \\
\text { While the collaborating }\end{array}$ & $\begin{array}{l}\text { The ability to implement control becomes } \\
\text { different with different as different measures are } \\
\text { use in interpreting the rules. } \\
\text { Norms of different groups and organisation } \\
\text { create confusion on what should be the } \\
\text { acceptable practice in the extended } \\
\text { communities. } \\
\text { Example } \\
\text { A practice that is acceptable in organisation A } \\
\text { becomes a taboo in organisation B and a } \\
\text { practice that is not known in organisation C. }\end{array}$ \\
\hline
\end{tabular}

AT (activity theory) at this stage is used to expose and highlight the complexities and extension that have potential to affect the credible certificate. An important feature of the relationship is the need for the realisation of congruence between the tools used (for example using electronic means or manual) and the subjects using it. However, where there is a lack of congruence between tools and subjects who use such tools (particularly when information cannot be shared) that become a potential failure point. Another failure point is the area of 
interpretation and application of the rules as they affect tools and impact on the subjects (stakeholders). Congruence is essential in reducing complexities caused by extension, but such is achievable as described by management staff of the case study organisation;

"I have seen over the years that for us to achieve our targets or goals there must be compromise [having to be on the same page if it means giving up some things] because achieving the aims of the establishment is the most paramount".

There is, therefore, the need for understanding collaborating stakeholder's perspectives, their strengths and capabilities, weaknesses and potential area of further collaboration as well as learning other aspects of the relationship to complement each other's perspective to (or "intending to") become mutually accountable (Katzenbach \& Smith, 1993).

Have established the potential for failures due to extension and its complexities and the fact that their success depends on networks of relationships (Rouse, 2012), a director in a sister organisation described how complexity is reduced and an overall objective is achieved. According to him it is through the use of specialised teams in complex and extended organisations;

"Teamwork, where different people come together to make the system work and by division of Labour, that is having different unit coming together to achieve a set goal, however, if a unit is faulty or is not active it will affect the entire production".

The division of labour described above is a specific one with collaborating partners using tools which can best help in achieving their aim. This finding is in line with the work of Landy \& Conte (2016) that argued for the use of teams to address productivity problems. However, such extension requires the organisation to manage and accommodate these relationships with a range of stakeholders and to maintain flexibility in these relationships which recognises and attempts to reconcile areas of deficiencies. This flexibility is achievable when a team is committed to an ideology that helps them achieve their stated goal (Engestrom, 2008). Accordingly, extended organisations rely and depend on such work of specialised teams/groups, and there are instances where such teams or groups like the one in this study cannot solve such skilled expertise problem. This situation may provoke the formation of knots as a way of dealing with an immediate skill problem in line with the study of Engeström et al. (1999).

The nature of dependency observed in the complex and extended organisation is seen as a way of getting things done especially in areas where the central agency lacks that expertise, at the same time the relationship is a way of sharing information needed for such collaborative operation. By way of proving the link between information sharing and team relationship, we use the study of Farrel (2008), and the explanation of the way relationships affect one another (teams) and need to achieve a shared object through the information they share. The observation carried out also identified the use of teams as a standard part of the case study organisation - such that it sinks to the level of operation and becomes a regular (and less visible) part of the organisation. This behaviour which has become part of the organisation may also be a source of tension and contradiction as other collaborating organisations may not think or act that way.

One characteristic observed is the deep sense of purpose which help the organisation in the setting to achieve success in line with Richards et al. (2012). The study characterised teams by deeper sense of purpose from all it members, not only that but according to them, the team will have motivated goals, and complement skills of one another by way of sharing information resulting in a fuller mutual accountability by a leader. Therefore, this paper argues that the same behaviour of complementing team abilities makes information to be shared within the team appropriately as each team is responsible for producing an output or that proportion of the shared common goal.

\section{Discussion}

The scenarios described in this paper are relatively representative in meeting the objectives of exploring collaborative information sharing in the complex and extended organisation. Understanding the phenomena help to answer the question of how these complexities and extension influence collaborative information sharing. The impact of extension is described as complex (IRM, 2014) and this complexity has made organisations use functional (specialised) teams as a way of getting things done especially in areas where the central organisation lacks such expertise and also as a coping strategy for the central organisation to solve the problem. However, the specialised nature of these teams means solving specialised work roles/problems. This is achieved by the complementary nature of such teams and the way relationships affect one another (Farrel, 2008; Richards et al., 2012; Landy \& Conte, 2016) and in doing so, they also share information to achieve that common goal. The data for the study emerged based on AT as a lens, which identifies the subjects involved in the research, and the use of 
software Nvivo to manage the data collected. Concepts that emerged from the data included two key concepts which are complexity and extension which fit with the dominant driver for the research. In identifying the complexities in the research settings activity theory as a framework was appropriate and suits the area of the research through the understanding of different sets of dialogue between diverse communities, networks of interrelated activities and division of labour. The third generation AT used shows the extended relating communities where discussion which includes information sharing is necessary and information sharing is needed by way of interacting with different activity systems in multiple relationships. The unit of analysis was various activities with a minimal of two interacting activity systems.

Factors in this paper that aid and support the use of teams are the specialised nature of task involved in the extended relationship. The extended nature only accommodates relationships with specialised expertise which is provided to fill the area such expertise is lacking in the central organisation. The sharing behaviour is based on information sharing by complementary abilities of members in the area of division of labour through the use of different tools. It has also been reported that the relationship which cut across entities have direct or indirect things in common and whose relations affect each other. The complementary nature of teams also makes them have deep sense of purpose which keeps them motivated in achieving the needed goals (Landy \& Conte, 2016). Consideration was given to how teams are used in other settings in the literature; however, the area of dependency with its complex nature and possibilities of failures and the significance need of information sharing like that of this setting seem to have received less attention.

To understand this new insight into this paper, existing areas of literature are used to support some themes, and the findings inform the results of this article. The analysis section is based on interview extracts and observations carried out during the data collection stage. The results of this qualitative piece of work are grounded in the data that express the personal experience of respondents within their work environment and is an individual's perception of their reality which varies between individuals.

The study has implications for practice by way of applying the knowledge to organisations that are involved in extensive collaboration and finding out if the results are implementable or not. More so a possible future direction is suggested by this work, which suggests finding how complex and extended organisation mitigate these complexities caused as a result of the extension. Finally, this study is planned for a work-based setting where the collaborative arrangement is based on extended relationships.

\section{Conclusion}

The paper presents a concept "complex and extended organisation" where complexity and extension are linked and seen as contributing to information sharing failures. The paper draws upon related literature on how complexity and extension influence collaborative information sharing. The framework used is activity theory which is available to understand both the tensions and contradictions in the activity system(s). It is also a very good lens for understanding the need for information sharing in the research setting and the understanding of tensions and contradictions which did provide failure points for analysing information failures. Key among these findings is the emergence of coping strategies which complex and extended organisations used in achieving their goals and sharing information. This is reported as through the use of teams/groups and teamwork which are observed in a different setting from non-complex and extended settings. The paper illuminates the collaborative information sharing behaviours, information and the importance of sharing in complex and extended settings. The article is different from the other settings as seen in other contexts as reviewed in the academic literature. The implication of this paper is both to practice and theory, and future directions are also suggested.

\section{References}

Aime, F., Humphrey, S., DeRue, D. S., \& Paul, J. B. (2014). The riddle of heterarchy: Power transitions in crossfunctional teams. Academy of Management Journal, 57(2), 327-352. http://dx.doi.org/10.5465/amj.2011.0756

Allen, D. K., Karanasios, S., \& Norman, A. (2014). Information sharing and interoperability: The case of major incident management. European Journal of Information Systems, 23(4), 418-432. http://dx.doi:10.1057/ejis.2013.8

Allen, D., \& Wilson, T. D. (2005). Action, interaction and the role of ambiguity in the introduction of mobile information systems in a UK police force. In Mobile Information Systems (pp. 15-36). Springer US. https://link.springer.com/chapter/10.1007/0-387-22874-8_2

Belbin, R. M. (2012a). Management teams. Routledge.

Belbin, R. M. (2012b). Team roles at work. Routledge. 
Belbin, R. M. (2012c). Beyond the team. Routledge.

Camarinha-Matos, L. M. (2004). New collaborative organizations and their research needs. In Processes and Foundations for Virtual Organizations (pp. 3-14). Springer US. Retrieved from https://ink.springer.com/chapter/10.1007/978-0-387-35704-1_1

Chengalur-Smith, I., Duchessi, P., \& Gil-Garcia, J. R. (2012). Information sharing and business systems leveraging in supply chains: An empirical investigation of one web-based application. Information \& Management, 49(1), 58-67. https://doi.org/10.1016/j.im.2011.12.001

Egolf, D., \& Chester, S. (2013). Forming storming norming performing: Successful communication in groups and teams. IUniverse.

Engeström, Y. (1999). 23 Innovative learning in work teams: Analyzing cycles of knowledge creation in practice. Perspectives on Activity Theory, 377.

Engeström, Y. (2000). Activity theory as a framework for analyzing and redesigning work. Ergonomics, 43(7), 960-974.

Engeström, Y. (2008). From teams to knots: Activity-theoretical studies of collaboration and learning at work. Cambridge University Press.

Engeström, Y. (2015). Learning by expanding: An activity-theoretical approach to developmental research (2nd ed.). Cambridge, UK: Cambridge University Press.

Engeström, Y., Kaatrakoski, H., Kaiponen, P., Lahikainen, J., Laitinen, A., Myllys, H., ... \& Sinikara, K. (2012). Knotworking in academic libraries: Two case studies from the University of Helsinki. Liber Quarterly, 21(34).

Farell, J. P. (2008). What is the extended enterprise?

Force, T. (2008). Task Force. Health Information Management and Informatics. Core competencies for individuals working with electronic health records.

Hilbert, M. (2016). Formal definitions of information and knowledge and their role in growth through structural $\begin{array}{llll}\text { change. Structural Change and Economic Dynamics, 38, } & \text { 69. }\end{array}$ https://doi.org/10.1016/j.strueco.2016.03.004

Hoch, J. E., \& Kozlowski, S. W. (2014). Leading virtual teams: Hierarchical leadership, structural supports, and shared team leadership. Journal of applied psychology, 99(3), 390. https://psycnet.apa.org/doi/10.1037/a0030264

Holman, D., Wall, T. D., Clegg, C. W., Sparrow, P., \& Howard, A. (Eds.). (2003). The new workplace: a guide to the human impact of modern working practices. John Wiley \& Sons.

Huo, B., Han, Z., Zhao, X., Zhou, H., Wood, C. H., \& Zhai, X. (2013). The impact of institutional pressures on supplier integration and financial performance: Evidence from China. International Journal of Production Economics, 146(1), 82-94.

Institute of risk management IRM. (2014). Extended Enterprise: Managing risk in complex $21^{\text {st }}$ century organizations. Executive summary. Retrieved from https://www.theirm.org/media/1155369/IRM-ExtendedEnterprise_A5_AW.pdf

Jagdev, H. S., \& Browne, J. (1998). The extended enterprise-a context for manufacturing. Production Planning \& Control, 9(3), 216-229.

Katzenbach, J. R., \& Smith, D. K. (1993). The wisdom of teams: Creating the high-performance organization. Harvard Business Press.

Landy, F. J., \& Conte, J. M. (2016). Work in the 21st Century, Binder Ready Version: An Introduction to Industrial and Organizational Psychology. John Wiley \& Sons.

Lawson, B., Petersen, K. J., Cousins, P. D., \& Handfield, R. B. (2009). Knowledge sharing in interorganizational product development teams: The effect of formal and informal socialization mechanisms. Journal of Product Innovation Management, 26(2), 156-172.

Lee, H. L., So, K. C., \& Tang, C. S. (2000). The value of information sharing in a two-level supply chain. Management science, 46(5), 626-643.

Liu, J., Huang, X., \& Liu, J. K. (2015). Secure sharing of personal health records in cloud computing: ciphertext- 
policy attribute-based signcryption. Future Generation Computer Systems, 52, 67-76.

Lund, D. B. (2015). Characteristics of the Principal Influencer in Organizational Buying Committees. In Proceedings of the 1989 Academy of Marketing Science (AMS) Annual Conference (pp. 350-354). Springer International Publishing.

Mason, J. (2002). Qualitative researching (2nd ed.). Sage Publications, London.

Mihm, J., Loch, C. H., Wilkinson, D., \& Huberman, B. A. (2010). Hierarchical structure and search in complex organizations. Management science, 56(5), 831-848.

Mishra, J. L., Allen, D. K., \& Pearman, A. D. (2011). Information sharing during multi-agency major incidents. Proceedings of the American Society for Information Science and Technology, 48(1), 1-10.

Pilerot, O. (2014). Making design researchers' information sharing visible through material objects. Journal of the Association for Information Science and Technology, 65(10), 2006-2016.

Provan, K. G., \& Lemaire, R. H. (2012). Core concepts and key ideas for understanding public sector organizational networks: Using research to inform scholarship and practice. Public Administration Review, 72(5), 638-648. https://doi.org/10.1111/j.1540-6210.2012.02595.x

Richards, B., Carter, N., \& Feenstra, F. (2012). High Performing Work Teams.

Robson, A., \& Robinson, L. (2013). Building on models of information behaviour: linking information seeking and communication. Journal of documentation, 69(2), 169-193. https://www.emerald.com/insight/content/doi/10.1108/00220411311300039/full/html

Rouse, M. (2012). Extended Enterprise. Tech Target. Retrieved from http://searchcio.techtarget.com/definition/Extended-enterprise [Accessed June 23 2014].

Schwandt, T. A. (1994). Constructivist, interpretivist approaches to human inquiry.

Smircich, L. (1983). Concepts of culture and organizational analysis. Administrative science quarterly, 339-358.

Tannenbaum, S. I., Mathieu, J. E., Salas, E., \& Cohen, D. (2012). Teams are changing: Are research and practice evolving fast enough? Industrial and Organizational Psychology, 5(1), 2-24.

Tracy, S. J. (2013). Qualitative research methods. UK: Wiley-Blackwell.

Tuckman, B. W., \& Jensen, M. A. C. (1977). Stages of small-group development revisited. Group \& Organization Studies, 2(4), 419-427. $\quad$ Retrieved from http://faculty.wiu.edu/PSchlag/articles/Stages_of_Small_Group_Development.pdf

Wong, C. W., Lai, K. H., Cheng, T. C. E., \& Lun, Y. V. (2015). The role of IT-enabled collaborative decision making in inter-organizational information integration to improve customer service performance. International Journal of Production Economics, 159, 56-65. https://doi.org/10.1016/j.ijpe.2014.02.019

\section{Copyrights}

Copyright for this article is retained by the author(s), with first publication rights granted to the journal.

This is an open-access article distributed under the terms and conditions of the Creative Commons Attribution license (http://creativecommons.org/licenses/by/4.0/). 